\title{
Yüksek Lisans ve Doktora Öğrencilerinin Tez Konusu Belirleme Kriterlerinin
}

\author{
İncelenmesi*
}

\section{Examination of Thesis Subject Determination Criteria of Postgraduate And}

\author{
Doctorate Students
}

Ferhat BAHÇECI**

Makalenin geliş tarihi: 09.05.2018

\author{
Leyla UŞENGÜL***
}

Kabul tarihi: 30.05 .2018

\section{$\ddot{\mathbf{O z}}$}

$\mathrm{Bu}$ araştırmanın amacı lisansüstü öğretimde yüksek lisans ve doktora öğrencilerinin tez konusu belirlerken dikkat ettikleri kriterleri incelemektir. Bu zorlu süreçte lisansüstü öğrencilerin en çok karşılaştıkları problem tez konusunu belirleme ve tez konusuna karar verme sürecidir. Bu araştırmada öğrencilerin tez konusu belirleme sürecinde dikkat edilen kriterler belirlenerek, bundan sonraki araştırma çalışmalarına 1şık tutacağı düşünülmektedir. Araştırmada yüksek lisans ve doktora öğrencilerinin tez konusu seçerken dikkat ettiği kriterlerin belirlenmesi amacıyla "tez konusu belirleme kriterleri” anketi geliştirilmiştir. Anket toplam 27 sorudan oluşmaktadır. Soru tipleri genel olarak Demografik, Olgusal ve Yargısal soru tiplerinden oluşmaktadır. İlk 5 soru demografik, sonraki 20 soru olgusal ve yargısal sorulardan, son iki soru ise yarı açık soru tiplerinden oluşmaktadır. Araştırmanın nitel kısmı için ise görüşme yöntemi uygulanmıştır. Geliştirilen anket 115 lisansüstü öğrencisine uygulanmış ve 5 kişi ile görüşme yapılmıştır. Verilerin analizinde yüksek lisans ve doktora öğrencilerine uygulanacak tez konusu belirleme kriterleri anketi ile aritmetik ortalama (x), standart sapma (s), frekans (f), yüzde (\%), t-testi, tek faktör anova testi kullanılmıştır. Elde edilmiş olan verilerin yorumlanmasında .05 anlamlılık düzeyi kabul edilmiştir. Uygulanan anketler ve görüşmeler sonucunda tez konusu belirlerken güncel, literatüre dayalı ve danışmanın alanına uygun konuların seçildiği tespit edilmiştir.

Anahtar Sözcükler: Lisansüstü Eğitim, Yüksek Lisans, Doktora, Tez

\begin{abstract}
The purpose of this research is to determine the criteria that masters and doctoral students pay attention to when choosing thesis topic in postgraduate education. In this challenging process, the most common problem for graduate students is the process of determining the thesis topic and deciding on the thesis topic. In this research, it is thought that the criteria to be considered in the process of determining thesis subject will be determined and will shed light on future research studies. In order to determine the criteria that the graduate and Ph.D. students took into consideration when choosing the thesis topic in the research, the "thesis topic determination criteria" questionnaire was developed. The questionnaire consists of 27 questions in total. Question types generally consist of the Demographic, Factual and Judicial question types. The first 5 questions are demographic, the next 20 questions are from factual and judicial questions, and the last two questions are semi-structured question types. The developed questionnaire was applied to 115 graduate students and 5 were interviewed. Arithmetic mean (x), standard deviation (s), frequency (f), percentage (\%), t-test, one-factor ANOVA test were used in the thesis subject determination questionnaire applied to graduate and doctoral students. A significance level of .05 was accepted in interpreting the obtained data. As a result of the questionnaires and interviews, it was determined that the topics that are appropriate for the field of consultant are based on the current, literature based and the thesis topic.

Keywords: Post-graduate Education, Master, Doctorate, Thesis

\footnotetext{
* Bu makale, İnönü Üniversitesi tarafından 24-26 Mayıs 2017 tarihleri arasında Malatya' da düzenlenen 11.Uluslararas1 Bilgisayar ve Öğretim Teknolojileri Sempozyumu'nda özet sözlü bildiri olarak sunulmuştur. ** Dr. Öğr. Üyesi, Fırat Üniversitesi, Eğitim Fakültesi Eğitim Bilimleri Bölümü, Elazığ, ferhatbahceci@ hotmail.com ***Öğretmen, Bahçeşehir Koleji, Elazı̆̆g, leyla.usengul@gmail.com
} 


\section{GİRIŞ}

Günümüzde hızla yayılan bilgi rekabeti artırmış ve alanda uzman olmak önemli hale gelmiştir. Üniversiteler bilimsel anlamda bilgiyi ortaya çıkarmak ve toplumsal gelişimi sağlamakla yükümlü kurumlar arasındadır (Saracaoğlu, 2008). Uzmanlaşmayı sağlamada üniversitelerden alınan lisans düzeyindeki eğitim yeterli değildir (Turhan \& Yaraş, 2013). Dört yıl süren lisans eğitiminin akabinde verilen lisansüstü eğitim, alanda uzmanlaşmayı sağlar (Sağlam, 2007'den akt. İpek Akbulut, Şahin ve Çepni, 2013).Yüksek lisans ve doktora eğitimi, araştırma ile bilginin oluşumuna destek olacak ve gelişme sürecinde bulunan toplumun ihtiyaçlarına cevap verecek öğretim elemanı ve bilim insanı yetiştirmeyi amaçlayıp, üniversitelerde lisansüstü kıdemlere gelmeyi sağlayan eylem şeklinde de tanımlanmıştır (Varış, 1972'den akt. İpek Akbulut, Şahin ve Çepni, 2013). Kişilerin meslek alanlarında donanımlı olmalarını sağlamak ve akademik çalışmaları artırmak gibi amaçları olan lisansüstü eğitim; bilimsel bir alanda derin bir şekilde çalışarak, alınan lisans eğitiminden daha yüksek seviyede etkinlik ve bilgi sahibi olmayı sağlayan eğitim programıdır (Köksalan, İlter ve Görmez, 2010). Başka bir ifadeyle lisansüstü eğitim programları bilgi üretimine katkıda bulunan ve araştırmaları destekleyen eğitimlerdir. Lisansüstü eğitimlerin en önemli işlevi akademisyen yetiştirilmesini sağlamaktır (Alkan, 2014).

Karakütük (1989) yüksek lisans ve doktora eğitiminin önem kazanmasını ve gelişmesini şu nedenlerle açıklamaktadır:

“1. Bilgi birikimleri, teknolojideki hızlı gelişim yükseköğretimden mezun olduktan sonra da lisansüstü eğitimi gerekli kılması.

2. Ülke kalkınmasında yüksek nitelikli insan gücüne ihtiyaç duyulması.

3. Bilim ve teknolojinin hızlı biçimde gelişmesi ve bu konuda üniversitelerin önemli bir rol üstlenmesi.

4. Temel eğitim süresinin uzaması ve çağ nüfusunun artması.

5. Yükseköğretimde okullaşma oranının artması ile birlikte öğretim üyesine olan gereksinimin de artmas1."

Bilimin öğretildiği ve üretildiği üniversite kurumlarında ilk olarak 19.yy başında Almanya'da başlayıp süreç ilerledikçe birden fazla ülkede de verilen lisansüstü eğitim, araştırma ile öğretimin birleşmesini daha çok güçlendirmiş ve devamlı hale getirmiştir (Türker, 2001).

Lisansüstü eğitim Türkiye'de, 1960 yıllarının sonlarına kadar yüksek lisans eğitimi olmadan sadece doktora eğitimi halinde 3-4 yıllık bir süreçte hoca-asistan ilişkisi şeklinde yürütülmüştür (Çakar, 1997). 1970'li yıllardan önce yüksek lisans sonrasında doktora şeklinde iki kademeye bölünüp bu kademelerde uygulanacak kurallar günümüze kadar pek çok kez değişime uğrayan yönetmelikler doğrultusunda devam ettirilmiştir (Çakar, 1997).

Enstitü, fakültelerde bulunan enstitüler, birbirine benzeyen bilim dallarında lisans sonras1 verilen eğitim-öğretim, uygulama ve bilimsel araştırma yapılan birimlerdir (2547 Sayılı YÖK Kanunu, 
3/f. Maddesi). Sözü edilen bu eğitim faaliyetleri genel olarak üniversite bünyesinde bulunan fen, sosyal, eğitim ve sağlık bilimleri gibi enstitülerce yürütülmektedir (Karaman \& Bakırc1, 2010). Yüksek lisans, lisans eğitimine dayanan eğitim ve araştırma sonuçlarını meydana çıkarmayı ve araştırma konularında bilimsel yöntemleri kullanma yeteneğini geliştirerek, uzmanlık olabilecek durumda araştırma ve eğitim etkinliklerini hedefleyen yükseköğretim programıdır (Karaman \& Bakırc1, 2010). Nitelikli insan gücü yetiştirmeyi ve uzmanlaşmayı amaçlayan lisansüstü eğitim, farklı alanları barındıran tezli - tezsiz yüksek lisans ve doktora programlarını kapsamaktadır. Tez ile sonlandırılan yüksek lisans eğitimi öğrencilerin bilimsel araştırma basamaklarını ve yöntemlerini kullanıp bilgiye ulaşıp, düzenleme, değerlendirme ve yorumlama yeteneklerini kazanmasını sağlar. Tezsiz yüksek lisans eğitimi, öğrencinin mesleki konularda bilgiye sahip olmasını ve var olan bilgiyi nasıl uygulaması gerektiğini öğretir (2547 Sayılı YÖK Kanunu, 3/f. Maddesi).

Doktora, lisans eğitimi, yüksek lisans ya da fen fakültesi ile eczacılık mezunlarınca Sağlık Bakanlığı tarafından konulan kurallara göre bir araştırma alanında kazanılımış uzmanlığa dayanıp, en az dört yarıyıllık dönemi kapsayarak özgün bir çalışmanın sonuçlarını ortaya çıkarmayı hedefleyen bir eğitim programıdır (Karaman \& Bakırc1, 2010). Yüksek lisans eğitimi, öğrencilerin bilimsel yöntemleri kullanıp bilgiye ulaşma, yorumlama ve değerlendirme kabiliyetinin kazanmayı amaçlamaktadır. Doktora eğitimi ise öğrencinin bağımlı olmadan araştırma yapmasını, bilimsel olayları geniş bir bakış açısıyla değerlendirerek yorumlamayı ve yeni sonuçlara ulaşmak için gereken aşamaları oluşturma kabiliyeti kazandırmayı amaçlamaktadır (Karaman \& Bakırcı, 2010).

Tez, ortaya koyulan önerme ve fikirleri içeren dokümanlardır. Tez bir alanda yapılacak çalışmaya belli bir bakış açısı kazandırır. Araştırma sürecinde ulaşılan bilgiler ve sonuçlar ile hipotez kanıtlanmaya çalışılır. Zorlu lisansüstü öğrenim süreci içerisinde öğrenciler ders, danışman ve tez konusu seçme, tez izleme komitesi belirleme, yeterlilik, tez önerisi verme, materyal geliştirme, tezi uygulama ve yazma gibi birden çok aşamayı birlikte yürütmektedir (Bakioğlu ve Gürdal, 2001). Çalışılacak tez konusu için yeterli literatür taramasının yapılmaması veya konunun önceden çalışılıp çalışılmadığını araştırılmadan konu belirlemesinin yapılması, daha önce fazlaca çalışılmış konular aynı biçimde, aynı yöntemlerle ele alınır (Oruç \&Ulusoy, 2008). Araştırma sonuçları öğrencilerin tez yazma sürecinde karşı karşıya geldikleri bu güçlüklere ek olarak; danışman, çalışma, kişisel yaşam, iş arkadaşları, maddi olanaksızlık gibi birçok zorlukla da karşılaştıklarını göstermiştir (Appel ve Dahlgren, 2003; Wright, 2003).

\section{Araştırmanın Amacı}

Araştırmanın amacı lisans eğitiminden sonra yüksek lisans ve doktora eğitimi alan öğrencilerin tez konularını belirlerken göz önünde bulundurdukları kriterlerin belirlenmesi için anket geliştirerek, lisansüstü eğitim alan öğrencilerin tez konusu belirleme kriterlerini ortaya koymak ve bundan sonraki çalışma sürecinde daha verimli tez konuları belirlemelerini sağlamaktır.

Alt problemler 
1. Bölümler arasında tez konusu seçme kriterlerine göre anlamlı farklılık var mıdır?

2. Katılımcıların cinsiyet ve yaş değişkenlerine göre tez konusu seçme kriterleri arasında anlamlı farklılık var mıdır?

Araştırmanın Önemi

Zorlu geçen bu süreçte lisansüstü eğitim alan öğrencilerin en fazla karşı karşıya geldikleri sorun tez konusuna karar verip, belirleme sürecidir. Bu çalışma ile tez konusu seçme sürecinde göz önüne alınan kriterler ortaya çıkarılıp bundan sonra yapılacak olan çalışmalara katkı sağlayacağı düşünülmektedir.

\section{YÖNTEM}

\section{Araştırma modeli}

Çalışma betimsel tarama modeli olarak yapılmıştır. Çalışma içeriğinde nicel ve nitel araçların birlikte kullanıldığı yakınsayan paralel karma desene dayalı bir araştırma gerçekleştirilmiştir. Buna dayanan araştırmalarda nitel ile nicel veriler aynı zamanda toplanıp, ayrı bir şekilde analiz edilir ve çıkarımlar birleştirilerek yorumlar yapılır (Creswell, 2012).

\section{Katılımc1 Grubu}

Çalışmanın nicel kısmında geliştirilmiş anketin uygulanabilmesi amacıyla katılımcı grubu Elazığ Fırat Üniversitesi Eğitim Enstitüsündeki yüksek lisans ve doktora öğrencileri olarak belirlenmiştir.

\section{Veri Toplama Araçlarının Geliştirilmesi}

Araştırmada nitel ve nicel veri toplama araçları uygulanmıştır. Aşağıda nitel ve nicel veri toplama araçlarıyla ilgili bilgi verilmiştir.

Çalışmada lisansüstü eğitim alan öğrencilerin tez konusu seçiminde dikkate aldıkları kriterleri belirlemek amacıyla "tez konusu belirleme kriterleri” anketi geliştirilmiştir. Ankette 27 soru bulunmaktadır. Genellikle demografik, yargısal, olgusal soru tipleri yer almaktadır. Anketin ilk beş sorusu demografik, 20 soru yargısal ve olgusal tipli soru, son ikisi ise yarı açık soru tiplerinden oluşmaktadır. Geliştirilen bu form iki uzman tarafindan da incelenmiş ve soru maddeleri üzerinden düzeltmeler yapılmıştır. Son hale getirilen anket uygulama ve etik kurul izni alınıp yüksek lisans ve doktora öğrencilerine uygulamaya hazır hale getirilmiştir. Ankete katılımda gönüllülük ilkesi esas alınmıştır. Anketin dikkatli bir şekilde uygulanması amacıyla verilerin bir bölümü uygulayıcıların gözetimi ile doldurulmuştur. Anketlerin uygulanması sırasında uygulayıcılar katılımcıları olumlu veya olumsuz hiçbir şekilde yönlendirmemiştir. Verilerin bir kısmı da mail yoluyla katılımcılardan toplanmıştır.

Araştırmada doktora öğrencileri ve öğretim üyeleri ile yapılacak görüşmeler için yarı yapılandırılmış görüşme formu oluşturulmuştur. $\mathrm{Bu}$ formda tez konusu seçme sürecinde dikkate alınması gereken kriterler ve yüksek lisans-doktora tezlerinin paralelliğinin verimliliği hakkında iki 
soruya yer verilmiştir. Görüşme içerik bilgisinde, görüşmelerin amacı, görüşme esnasında dikkat edilecek esaslar, görüşmenin nasıl yapılıp kaydedileceği hakkında bilgiler yer almıştır.

\section{Verilerin Analizi}

Araştırmada nicel ve nitel veriler toplanıp, analiz edilmiştir. Verilerin analizi yapılırken kullanılan yöntemler aşağıda belirtilmiştir. Analizler yapılırken lisansüstü eğitim alan öğrencilere uygulanan tez konusu belirleme kriterleri anket verilerinde standart sapma (s), aritmetik ortalama (x), frekans (f), t-testi, yüzde (\%), tek faktör anova testi kullanılmıştır. Ortaya çıkan veriler yorumlanırken.05 anlamlılık düzeyi kabul edilmiştir. Kayıp veriler incelendiğinde çok az sayıda eksik veri olduğu saptanmıştır. Bundan dolayı kayıp veriler için istatistiksel bir değer atanmamış, veriler orijinal halleriyle analiz edilmiştir. Araştırmada gerçekleştirilen yarı yapılandırılmış görüşmeler analiz edilirken öncelikle görüşme sırasında yapılan ses kayıtları yazıya dökülmüştür. Daha sonra betimsel ve içerik analizler birlikte yapılıp görüşme esnasında vurgu yapılan temalar belirlenerek kodlanmıştır. Katılımcıların kodları açıkça belirtilerek alıntılar bu şekilde düzenlenmiştir. Elde edilen temalar alıntılarla desteklenip yorumlamalar yapılmıştır.

\section{BULGULAR}

Yüksek lisans ve doktora öğrencilerinin tez konumu belirleme kriterleri anketinde en yüksek puan veriler maddeler Tablo 1'de sunulmuştur.

Tablo 1

Yüksek lisans ve doktora öğrencilerinin tez konusu seçerken en çok dikkat ettiği kriterler

\begin{tabular}{|c|c|c|c|}
\hline Maddeler & $\mathrm{f}$ & $\overline{\mathrm{X}}$ & Ss \\
\hline 1. Tez konumu seçerken ilgi alanıma uygun olmasına dikkat ederim. & 114 & 4,41 & ,870 \\
\hline 2. Tez konumu seçerken güncel bir konu olmasına gayret gösteririm. & 114 & 4,39 & 1,0 \\
\hline $\begin{array}{l}\text { 3. Tez konumu seçerken teknolojik araçlardan faydalanarak araştırma } \\
\text { yaparım. }\end{array}$ & 115 & 4,35 & 1,14 \\
\hline 4. Tez konumu mutlaka literatür taramasından sonra belirlerim. & 115 & 4,22 & 1,34 \\
\hline $\begin{array}{l}\text { 5. Tez konumu seçerken belirlenen sürede bitirilebilecek bir çalışma olmasına } \\
\text { dikkat ederim. }\end{array}$ & 115 & 4,19 & 1,19 \\
\hline $\begin{array}{l}\text { 6. Tez konumu seçerken uluslararası indeksli dergilerde yayınlanabilecek bir } \\
\text { çalışma olmasına özen gösteririm. }\end{array}$ & 115 & 4,03 & 1,06 \\
\hline $\begin{array}{l}\text { 7. Tez konumu seçerken kendi araştırma ve düşüncelerim doğrultusunda } \\
\text { seçerim. }\end{array}$ & 115 & 4,02 & ,93 \\
\hline
\end{tabular}

Tablo 1'de görüldüğü gibi tez konusu belirleme kriterleri anketinde katılımciların en yüksek puanladıkları maddenin "Tez konumu seçerken ilgi alanıma uygun olmasına dikkat ederim." Maddesi olduğu görülmüştür $(\bar{X}=4,41)$. İkinci en yüksek katılımın "Tez konumu seçerken güncel bir konu olmasına gayret gösteririm.” maddesi olduğu gösterilmiştir $(\bar{X}=4,39)$. Katılımcıların en yüksek puanladıkları üçüncü maddenin "Tez konumu seçerken teknolojik araçlardan faydalanarak araştırma yaparım.” İfadesi olduğu görülmüştür $(\overline{\mathrm{X}}=4,35)$.

Tablo 2

Yüksek lisans ve doktora öğrencilerinin tez konusu seçerken en az dikkat ettiği kriterler 


\begin{tabular}{llll}
\hline Maddeler & $\mathrm{f}$ & $\overline{\mathrm{X}}$ & $\mathrm{Ss}$ \\
\hline 1.Tez konumu seçerken danışman hocamın önerisini dikkate almam. & 114 & 1,72 & 1,14 \\
\hline 2. Tez konumu seçerken bilimsel kaynaklardan yararlanmam. & 115 & 1,72 & 1,77 \\
\hline 3. Tez konumu seçerken diğer kişilerin düşüncelerini önemsemem. & 114 & 2,07 & 1,16 \\
\hline $\begin{array}{l}\text { 4. Tez konumu seçerken günlük yaşamla ilişkili olmasına dikkat } \\
\text { etmem. }\end{array}$ & 115 & 2,32 & 2,05 \\
\hline
\end{tabular}

Tablo 2'de görüldüğü gibi ankette katılımcıların en düşük puanladığı maddenin “Tez konumu seçerken danışman hocamın önerisini dikkate almam.” İfadesi olduğu görülmüştür ( $\bar{X}=1,72)$. İkinci en düşük puanı alan ise "Tez konumu seçerken bilimsel kaynaklardan yararlanmam." Maddesi olmuştur ( $\overline{\mathrm{X}}=1,72)$.

Araştırmanın bu nicel sonuçlarına ek olarak nitel kısımda yapılan görüşmelerde katılımcıların ankette yer alan maddelere verdikleri yanıtlarla benzer temalar ortaya çıkmıştır.

“Ĕ̆er danışman seçilmişse danışmanın alanına uygun, idare edebileceği, kişinin sevdiği ve ilgisi olan bir konuda çalışmak lazım. Sevebileceğin alanı bilmek için de ĕger doktoradaysan az çok okuma yapmış oluyorsun ama yüksek lisansta bol bol farklı konular okumak lazım ki o konularda ne var ne yok ilgimi çekiyor mu çekmiyor mu işte danışman hocamla bu çalışmayı yapabilir miyiz yapamaz mıyız buna paralel giderek çalışmak lazım. Onun dışında aslında trend konuların hem avantajı var hem dezavantajı var 5-10 yılı aşmış konular birazcık slkıntılı. Çünkü alanda sürekli kendimizi geliştirmemiz gerekiyor. Güncel tutmak önemli ama bir yandan da sirf güncel çalışacağım diye istemediğin veya danışmanının yürütemeyeceği konuda çalışmak veya hakim olamayacağın konuda çalışmak dezavantajlı çünkü güncel olan konuda çok fazla bilgi yok. Bilgi olmadiğı için o bilgiyi sen üretiyorsun, o bilgiyi üreten kişilerden biri oluyorsun hatalı üretme ihtimali çok yüksek dolaylsılla dikkat etmek lazım. Doktora tezlerinde özellikle orijinal bir konu seçmek lazım. Çalışılmamış, çok küçük bir nokta bulunan burda ben bunu söylüyorum diyebileceğin bir konu olması lazım." (K2)

Yukarıda verilen bu alıntı ankette yer alan ilgi alanına uygun, güncel ve danışman hocanın alanına paralel, gerekli literatür taraması yapılan maddelerle örtüşmektedir.

Aşağıda başka bir görüşmeci ise yine anket maddelerinde yer alan güncel, literatür taramasından sonra ortaya çıkan konuların seçilmesi gerektiğini vurgulamıştır.

“Tez konusu seçerken bir defa literatürün gösterdiği açılları bulmak bana göre en önemlisi yani tez konusunu böyle direkt manavdan meyve seçer gibi değil de alana hakim olduktan sonra bir konu üzerinde seçmek daha mantıkll. Kişinin kendi ilgisine uygun bir konu olması önemli Yani üzerinde zevkle çalışabilmeli ve hani bazı konular literatürde balon gibi patlayıp çok çabuk sönen kısa bir süre sonra önemini kaybeden konular varken sağlam temeli olan konuların seçilmesi araştırmacı açısından avantajlı oluyor. Danışmanın etkisi iki şekilde olabilir. Birincisi danışmanın hâlihazırda üzerinde çalıştı̆̆ bir konu bir proje varsa o projenin bir boyutuyla yl doktora öğrencisi çalışabilir. Fakat daha çok tavsiye edilen yl derslerinde aldıkları ile birlikte kafasında bir konuyu oluşturup o konuya yoğunlaşması. Çünkü lisansüstü derslerde birçok okuma yapıyor, birçok ödev hazırllyor. Bak bu konu 
güzelmiş birçok araştırma yapılmış ama eksik kalmış olduğu noktalarda bence yl ögrencisi bir takım konular söyleyebilir. Mutlaka öğrenci konu getirmeli ya da hoca vermeli diye bir şey yok. ”(K3)

Bir başka görüşmeci ise literatür taramasının öneminden bahsetmiş ve danışman hocanın etkisinden söz etmiştir.

“...Tez konusu yl ve doktora döneminde en önemli safhalardan bir tanesidir. Doğru seçilemeyen tez konusu yl veya doktora tezinin bitmemesine sebep olur. Bu yüzden seçme sürecindeki kriterler önemlidir. Öncelikle konu alanına yatkınlık, alana hakimiyet, alanı araştırmak önemlidir. İkincisi danışman hocasından ne kadar destek alabileceği ne yapabileceği. Üçüncüsü de alana sağlayacağı katkı. Buna dikkat etmek lazım. Alana katkı sağlayacak mı yoksa sadece sırf ortaya biş̧ey çıkarmak için mi yapılıyor. Çünkü tez konusu bu tezi ben yaptım, bu sonuçları buldum. Alana, bilime faydası var diye ortaya çıkan bir şey. ” (K1)

Tablo 3

Tez konusu Belirleme Kriterlerinin Cinsiyete Göre T-Testi Sonuçları

\begin{tabular}{ccccccc}
\hline Cinsiyet & $\mathrm{N}$ & $\mathrm{X}$ & $\mathrm{S}$ & $\mathrm{sd}$ & $\mathrm{t}$ & $\mathrm{p}$ \\
\hline Kadın & 52 & 3,46 &, 28 & 112 & 2,01 &, 047 \\
\hline Erkek & 62 & 3,34 &, 35 & & & \\
\hline
\end{tabular}

Tablo 3 incelendiğinde yüksek lisans ve doktora öğrencilerinin tez konusu belirleme kriterlerinin cinsiyet değişkenine göre anlamlı bir farklılık göstermediği görülmüştür. Kadın ve erkeklerin tez konusu belirleme kriterlerinin birbirinden farklı olmadığı görülmektedir.

Tablo 4

Tez konusu Belirleme Kriterlerinin Bölümlere Göre T-Testi Sonuçları

\begin{tabular}{ccccccc}
\hline Bölüm & $\mathrm{N}$ & $\mathrm{X}$ & $\mathrm{S}$ & $\mathrm{sd}$ & $\mathrm{t}$ & $\mathrm{p}$ \\
\hline BÖTE & 21 & 3,48 &, 20 & 112 & 1,37 &, 173 \\
\hline Diğer & 93 & 3,37 &, 35 & & &
\end{tabular}

Tablo 4 incelendiğinde yüksek lisans ve doktora öğrencilerinin tez konusu belirleme kriterleri bölümlere göre anlamlı bir farklılık göstermemektedir. BÖTE ve diğer (sınıf öğr., eğitim prog,.ilköğretim mat, ...) tez konusu belirleme kriterlerinin birbirinden farklı olmadığı görülmektedir.

Tablo 5

Tez konusu Belirleme Kriterlerinin Lisansüstü Dereceye Göre T-Testi Sonuçları

\begin{tabular}{ccccccc}
\hline Derece & $\mathrm{N}$ & $\mathrm{X}$ & $\mathrm{S}$ & $\mathrm{sd}$ & $\mathrm{t}$ & $\mathrm{p}$ \\
\hline Yüksek lisans & 84 & 3,40 &, 33 & 112 &, 54 &, 586 \\
\hline Doktora & 30 & 3,36 &, 32 & & &
\end{tabular}

Tablo 5 incelendiğinde yüksek lisans ve doktora öğrencilerinin tez konusu belirleme kriterleri lisansüstü derecelerine göre anlamlı bir farklılık göstermediği görülmüştür. Yüksek lisans ve doktora öğrencilerinin tez konusu belirleme kriterlerinin birbirinden farklı olmadığı saptanmıştır. 


\section{TARTIŞMA, SONUÇ VE ÖNERİLER}

Nitel ve nicel yöntemlerin bir arada kullanıldığı bu karma desende tasarlanan çalışmada, yüksek lisans ve doktora öğrencilerinin tez konusu belirleme kriterleri incelenmiştir. Tez yazma sürecinde danışan öğrencilerin çok fazla desteğe ihtiyacı vardır; Barnes, Williams ve Stassen'na (2012) göre öğrenciler desteği en fazla tez danışmanlarından bekliyorlar. Danışmanla öğrenci arasındaki güçlü ilişki öğrencilerin tez yazma sürecinde karşı karşıya geldikleri olumsuzlukların sonuçlarını en aza indirmek ve kolay çözülebilir bir duruma getirmek açısından önemlidir (Gelso, 1997). Kalem ve Akman (2007)'ın da yaptıkları araştırmada tez konusu seçme sürecinde zorluklar yaşanıldığı tespit edilmiştir. Karadağ ve Ay (2007) da yaptıkları araştırmada, kaynaklara ulaşılmaması, istenilen konunun çalışılmaması, danışmanın yeterli dönüt verememesi, danışman ile uzmanlık alanının farklı olması, özgün bir konu bulmanın zorluğu şeklinde araştırma konusunun belirlenmesini zorlaştıran nedenler olarak bulmuşlardır.

Tez yazma sürecinin en zorlu aşaması tez konusu belirleme kısmıdır. Barutçu ve Onaylı (2016) yaptıkları çalışmada, konu belirlerken katılımcılar zorlanmadıklarını söyleseler de yaşadıkları ufak zorlukları; tez danışmanının ilgi alanına giren ortak bir konu bulamama, konuyu daraltamama ve karar verememe olarak belirtmişlerdir. Çalışmadaki nitel ve nicel bulgular birlikte değerlendirildiğinde, yüksek lisans ve doktora öğrencilerinin tez konusu belirlerken; konunun güncel, kişinin ilgi alanına uygun, araştırma ve düşünceleri doğrultusunda, belirlenen sürede bitebilecek bir çalışma olmasına dikkat ettikleri görülmüştür. Bu bağlamda öğrencilerin her düzeyde gerekli araştırmaları yapmaları, ilgi alanlarına uygun konuları belirlemeleri, güncel konuları takip etmeleri önerilmektedir. Öğrencilerin ilgi alanı olmayan bir konuya çalışmaları performanslarını ve süreci olumsuz şekilde etkileyecektir. Rudd (1991)'un da söylediği gibi çalışmaya başlarken ilgilenilen bir konuya zamanla duyulan ilgi azalırsa tezin zamanında bitmesinde problem çıkmaktadır.

Yapılan görüşmelerden çıkan sonuçlara bakıldığında danışman hoca seçiminin tez konusunu etkilediği görülmüştür. Alan taraması yapıldığında danışman etkisinin yüksek olduğu saptanmıştır. Akbulut ve arkadaşlarının (2013) yaptığı çalışma incelendiğinde, araştırmaya katılanların tez konusu seçmeyle ilgili görüşlerine bakıldığında, danışmanlarının konu seçiminde etkilerinin olduğu çıkarımı desteklenmektedir. Yüksek lisans ve doktora öğrencilerinin tez yazma sürecinde kendi alanına uygun tez çalışmasını birlikte yürütebileceği bir hoca seçmeleri önerilmektedir. Çünkü danışman hoca ilgili konu alanına ne kadar hâkim ise danışanına da bir o kadar verimli rehberlik eder. Aksi durumda öğrenciler araştırmalarındaki kavramları iyi bir şekilde sınırlandıramayacaklardır (Kiley, 2009). Fakat danışmanlar bu süreçte olması gerektiğinden fazla müdahalede bulunurlarsa süreç içinde öğrencilerin yaratıcılıklarını kullanmaları çok fazla mümkün olamayacaktır (Bakioğlu ve Gürdal, 2001).

Görülen başka bir sonuç ise tez konusunun mutlaka literatür taraması yapıldıktan sonra gerekli teknolojik araçlar yardımıyla ya da kütüphaneler aracıllğıyla kaynaklar tarandıktan sonra belirlenmesi gerektiğidir. Öğrenciler ne kadar da fazla literatür tarasalar, notlar alsalar da literatüre eleştirel gözle 
bakmadıkları zaman, verimli bir çalışma konusubelirlemekte zorluk yaşamaya devam edeceklerdir (Akbulut, Şahin ve Çepni, 2013). Tez konularının farklı disiplinler arası bir çalışma olması, proje desteği verilebilecek bir konu olması, alan ile ilgili gelecekteki çalışmalara kaynak olması tez konusunun kalitesini artıracaktır. Hart'a (1998) göre, alanyazın taraması araştırmacıya konu ile ilgili kavramsal çerçeve oluşturmayı sağladığı gibi araştırmanın gerekliliği konusunda araştırmacıyı ikna eder.

Doktora düzeyindeki öğrencilerin yüksek lisans döneminde yazdıkları tez konusundan genel olarak memnun olduklarını geçmişe dönme şansları olsa yine aynı konuyu seçeceklerini belirtmişlerdir. Yüksek lisans teziyle doktora tezinin benzer konu olmasının kişiyi alanda uzmanlaştıracağı için verimli olduğu sonucu ortaya çıkmıştır. Ancak Akbulut ve arkadaşlarının (2013) yaptığı çalışmaya göre katılımcıların doktoraya yeniden başlama imkânları olsaydı süreç içerisinde edindikleri tecrübeleri doğrultusunda izleyecekleri yolun farklı olacağı da görülmektedir.

Danışmanlar doktora öğrencilerinin öğrenci merkezli ve aktif bir halde öğrenmelerini sağlamalı ve danışanların araştırmacı yönlerini geliştirmelerine imkân sağlamalıdır (Styles ve Radloff, 2001). Gardner'ın (2008)'de belirttiği gibi doktora çalışmalarının amacı özgürce danışanların ilgi alanları çerçevesinde, özgün araştırma yapabilen kişiler yetiştirmektir. Bu amaç doğrultusunda danışmanların danışanlarına karşılaştıkları zorlukları aşmada destekçi ve rehber olmaları beklenmektedir.

Tez konusu belirleme kriterlerinin cinsiyete, yaşa, bağlı bulunduğu bölüme, lisansüstü düzeyine göre farkl1lık göstermediği görülmüştür. Lisansüstü öğrenim gören kadın ve erkeklerin benzer kriterlere göre konu seçimi yaptıkları saptanmıştır. Yüksek lisans ve doktora yapan öğrenciler araştırma türlerini daha çok deneysel, uygulamalı ve temel sıralamasına göre yapmak istediklerini belirtmişlerdir.

\section{KAYNAKÇA}

Akbulut, H. İ., Şahin, Ç., \& Çepni, S. (2013). Doktora tez sürecinde karşılaşılan problemlerin belirlenmesi: Eğitim fakültesi örneği. Dicle Üniversitesi Ziya Gökalp Eğitim Fakültesi Dergisi, 20, 50-69

Alkan, G. (2014). Türkiye'de muhasebe alanında yapılan lisansüstü tez çalışmaları üzerine bir araştırma (1984-2012). Muhasebe ve Finansman Dergisi, 61, 41-52.

Appel, M., \& Dahlgren, L. (2003). Swedish doctoral students experiences on their journey

Bakioğlu, A., \& Gürdal, A. (2001). Lisansüstü tezlerde danışman ve öğrencilerin rol algıları: yönetim için göstergeler. Hacettepe Üniversitesi Eğitim Fakültesi Dergisi, 21, 9-18.

Barnes, B. J., Williams, E. A. ve Stassen, M. L. A. (2012). Dissecting doctoral advising: A comparison of students' experiences across disciplines. Journal of Further Higher Education, 36, 309-331.

Barutçu, F., \& Onayl1, S (2016). Tez sürecinde karş1laş1lan zorluklar. Building. Scandinavian Journal of Educational Research, 47 (1), 89-110. Doi.10.14527/9786053183563.042. 
Çakar, Ö. (1997), "Fen Bilimleri Alanında Bilim Adamı Yetiştirme: Lisansüstü Eğitim, TÜBA Bilimsel Toplantı Serileri 7, Ankara. Eğitim”, TÜBA Bilimsel Toplantı Serileri:7, ss. 65-75.

Gardner, S.K. (2008). "What's Too Much and What's Too Little?”: The Process of Becoming an Independent Researcher In Doctoral Education, The Journal of Higher Education, 79 (3), 326350. doi.org/10.1080/00221546.2008.11772101

Gelso, C. J. (1997). The 1995 Leona Tyler address: The making of a scientist in applied psychology: An attribute by treatment completion. The Counseling Psychologist, 25, 307-320.

Gürdal, A., Bakioğlu, A., \& Öztuna, A. (2010). Fen bilgisi eğitimi lisansüstü tezlerinin incelenmesi. Buca Eğitim Fakültesi Dergisi, (17), 53-58. http://dx.doi.org/10.17522/nefefmed.54132

Hart, C. (1998). Doing a literature review. London: Sage Publications. Journal of Further and Higher Education, 25 (1), 97-106.

Kalem, G. ve Akman, İ. (2007). Lisansüstü Öğrencilerin Proje ve Tez Çalışmaları Sorunları ve Çözüm Önerileri. Eğitim Bilimleri Enstitüsü III. Lisansüstü Eğitim Sempozyumu Bildiriler Kitab1, Eskişehir.

Karakütük, K. (1989). Türkiye'de lisansüstü öğretim, sorunları ve çözüm önerileri. Ankara Üniversitesi Eğitim Bilimleri Fakültesi Dergisi, 22 (1), 505-528.

Karaman, S., \& Bakırcı, F. (2010). Türkiye'de lisansüstü eğitim: sorunlar ve çözüm önerileri.

Kiley, M. (2009). Identifying Threshold Concepts and Proposing Strategies to Support Doctoral Candidates. Innovations in Education and Teaching International. 46( 3), 93-30.

Köksalan, B., İlter, İ., \& Görmez, E. (2010). Sınıf öğretmeni adaylarının sosyo-kültürel özellikleri ve lisansüstü eğitim isteklilikleri üzerine bir çalışma (Fırat, Erzincan ve İnönü Üniversitesi sınıf öğretmenliği Anabilim Dalı örneği). Ahi Evran Üniversitesi Kırşehir Eğitim Fakültesi Dergisi, 11 (3). 277-299.

Oruç, Ş., \& Ulusoy, K. (2008). Sosyal Bilgiler Öğretimi Alanında Yapılan Tez Çalışmaları. Selçuk Üniversitesi Ahmet Keleşoğlu Eğitim Fakültesi Dergisi, 26, 121-132.

Rudd, E. [1985] A New Look at Postgraduate Failure, Guilford:SRHE:Nfer/Nelson, Brown G. ve Atkins, M. [1991]Effective Teaching in Higher Education, Routledge, London.

Saracaloğlu, A. S. (2008). Lisansüstü öğrencilerin akademik güdülenme düzeyleri, araştırma kaygıları ve tutumları ile araştırma yeterlikleri arasındaki ilişki. Yüzüncü Yıl Üniversitesi Eğitim Fakültesi Dergisi, 5(2). 179-208

Styles, I., \& Radloff, A. (2001). The Synergistic Thesis: Student and Supervisor Perspectives. 25 (1), 97 106, DOI:10.1080/03098770020030533

Suna, Ç., Karadăg, R. \& Selanik Ay, T. (2007). Yüksek lisans programı öğrencilerinin bilimsel araştırma sürecinde karşılaşlan sorunlara ilişkin görüşleri. Eğitim Bilimleri Enstitüsü, III. Lisansüstü Eğitim Sempozyumu Bildiriler Kitabı, Eskişehir. 
Turhan, M., \& Yaraş, Z. (2013). Lisansüstü Programların Öğretmen, Yönetici ve Denetmenlerin Mesleki Gelişimine Katkısı. Elektronik Sosyal Bilimler Dergisi, 43 (43), 200-218.

Türker, R. K. (1997). Bilim Adamı Yetiştirme: Dünyada ve Türkiye'de Lisansüstü Eğitim. Ankara: TÜBA, Bilimsel Toplantı Serileri 7. (s.21-48).

Varış, F. (1972). Türkiye'de Lisansüstü Eğitim "Pozitif Bilimlerde". Ankara Üniversitesi Eğitim Fakültesi Yayınları, 34.

Yükseköğretim Kanunu. Erişim Adresi: http://www.yok.gov.tr/content/view/1002. Erişim tarihi: 30.04.2018.

\author{
Extended Abstract
}

In the information age that we are in, the rapidly increasing and spreading information has strengthened the competition and made the specialization more important. Universities are the most important institutions that provide the emergence of scientific knowledge and social development. Today, education at the undergraduate level in universities is not enough to provide specialization. The post-graduate education program is a four-year post-graduate education, offering post-graduate and doctoral degrees and specializing in science. The postgraduate education is also defined as an activity that contributes to science through research, and aims to raise scientists and teaching staff to meet the needs of the developing society and to have a college graduate rating. The purpose of the graduate education is to enable the student to acquire knowledge through the scientific research, interpretation and evaluation of the information. In the challenging postgraduate education process, students are carrying out many steps such as choosing a course, choosing a supervisor, choosing a thesis topic, determining qualification, thesis supervision committee, thesis proposal, material development. Making the subject determination without searching the literature for the subject of the thesis to be worked on or investigating whether the topic is already worked or not, the subjects that have been studied before are handled in the same way. In addition to the difficulties encountered by the students in the thesis writing process, study, consultant, colleagues, personal life, financial impossibility, etc. has faced many challenges. The aim of this research is to develop a questionnaire to determine the criteria that the graduate and doctoral students take into consideration when choosing the thesis topic in post graduate education and to determine the criteria that the graduate and doctorate students should take into consideration when choosing the thesis topic and then to select the more healthy thesis topics in the following period. In this challenging process, the most common problem encountered by graduate students is the process of deciding on the thesis topic. In this research, it is thought that the criteria to be considered in the process of determining thesis topic will be determined and will shed light on future research studies. The research was done as a descriptive research in the survey model. In the scope of the study, a convergent parallel mixed research design, using both qualitative and quantitative data collection tools was carried out. Qualitative and quantitative data are collected simultaneously, analyzed separately, and the conclusions are combined and interpreted. For the implementation of the questionnaire developed in the quantitative dimension of the research, the participant group constitutes the students who have master and doctorate education at Elazığ Firat University Educational Institute. The "thesis topic determination criteria" questionnaire developed for the purpose of determining the criteria that the graduate and doctoral students took into consideration when choosing the thesis topic was developed in the research. The questionnaire consists of 27 questions in total. Question types generally consist of the Demographic, Factual and Judicial question types. The first 5 questions are demographic, the next 20 questions are from factual and judicial questions, and the last two questions are semi-open question types. This form was further investigated by 2 experts and reorganized through the materials. The finished taking the questionnaire ethical committee approval and permit application has been made ready to practice with masters and doctoral students. Volunteering was the basis for all participants to implement quantitative data collection tools. Some of the data has been filled in under the supervision of researchers so that the data collection tools can be filled more carefully. During the filling of the questionnaires, the researchers refrained from directing the participants positively or negatively. Another Part of the data was also collected via e-mail. This mixed-qualitative study, in which qualitative and quantitative methods are used together, examines the criteria for determining the thesis topic of masters and doctoral students. The most challenging stage of the thesis writing process is to determine the thesis topic. When the quantitative and qualitative findings obtained in the research are evaluated 
together, the thesis topic of master and Ph.D. students is determined; it has been observed that the subject is up to date, in accordance with the interests of the person, in the direction of research and thought, to be a study that can be completed in the determined time. In this context, it is suggested that students should carry out necessary researches at all levels, determine appropriate topics for their interests, and follow current topics. Studies of a subject that is not of interest to students will affect their performance and process in a negative way. Reported, when the interest in time began to decrease as the topic of interest began to be researched, there was a problem in completing the thesis in time. Judging from the results of the interviews, it was seen that the selection of the consultant teacher influenced the thesis topic. When the field scan was performed, the consultant effect was found to be high. When the study done by Akbulut and his colleagues is examined, it is supported that the deductions of the consultants are effective in determining the topic, considering the opinions of the researchers regarding the thesis topic determination. Master and Ph.D. students are advised to choose a teacher who will be able to carry out a thesis study suitable for their field in the thesis writing process. This is because the consultant can guide the student in a better way if he / she dominates the subject area. Otherwise, students will not be able to draw well the boundaries of the concepts in the study areas. However, if the consultants intervene too much in the process, it will not be possible to use the creativity of the students in this process too much. Another conclusion is that the thesis topic must be determined after the literature search has been done, after the necessary technological tools have been used or after the resources have been scanned through the libraries. No matter how much literature is searched by students, if they take notes, they will continue to have difficulty in finding an effective research topic when they cannot critically examine the literature. The fact that the thesis topics are interdisciplinary is a subject that can be given support of the project and it will increase the quality of the thesis which will be the source for future studies related to the field. Ph.D. students stated that they were generally satisfied with the thesis they had written in the postgraduate period, but they would choose the same topic if they had the chance to go back to the past. The conclusion is that the master's thesis is similar to the doctoral thesis, which is efficient for specializing in the field. However, according to Akbulut and his colleagues.if the participants had the possibility to start the doctor again, it would also be seen that the way they will follow in the course of their experience in the process will be different. It was seen that the criteria of determining the thesis topic did not differ according to sex, age, division, graduate level. It has been determined that female and male who are studying in the graduate school choose subject according to similar criteria. The graduate and doctoral students stated that they would like to make research types according to their experimental, practical and basic order. 